\section{TEACHING STRESS MANAGEMENT}

Sir, the article titled Dentist suicides ${ }^{1}$ is highly thought provoking and we thank Paul Hood's widow for allowing it to be published. As dental education in primary care outreach settings becomes increasingly common, clinical training is often framed by a live PDS+ NHS contract dealing with UDAs and KPIs. ${ }^{2}$

Final year dental students are already having to cope with the stress of the National Assessment for Foundation Training and the possibility of a low national ranking (and consequently no foundation training place available), all their various online computer assessments and those hurdles which others will only too readily remember of finals case presentations, OSCEs and traditional written and viva examinations. One of our roles as educators is to ease the transition into foundation training, handing over these exceptionally personable, bright and talented young professionals to vocational trainers. In support of this, we give our student colleagues (dental, hygiene/therapy and dental nursing) formal sessions on stress awareness and management.
There is an interesting contrast with the editorial in the same issue ${ }^{3}$ focusing on the profession taking a more holistic approach to our patients' health and wellbeing and being an integrated part of the healthcare team. However, if additional screening, such as blood pressure checks, are to be an extra burden to already over stretched dentists, realistic funding has to be put in place to provide for the additional members of the dental teams to achieve these important diagnostic and preventive general health measures.

Privately, we do worry about the environment in which our young colleagues will have to work and how they will cope with all the competing pressures of modern dental practice.

\section{R. Radford, J. M. Colley, P. Hellyer} Portsmouth

1. Renshaw J. Dentist suicides. Br Dent J 2013; 215: 593-594.

2. Radford D R. A personal perspective: breaking new ground in Portsmouth in the integrated dental education and professional care. HERN-J 2011; 2: 67-71.

3. Hancocks S. The hole and the whole. Br Dent J 2013; 215: 541.

DOI: 10.1038/sj.bdj.2014.10 geared towards the mentally stimulating challenges of consultation, diagnosis and treatment planning. Treatment is at the more complex end of the restorative scale as my therapists undertake the more routine work.

If we want this style of working and a viable business I suspect we need to educate our patients to value and ask for it whether under NHS or private contract. Politicians listen to their voters; more cost effective dental care is good for everybody.

The sorry state of NHS dental care is a complex issue. I sincerely hope that the result of the trials is a serious shift towards preventative, patient-centred dentistry, enshrined in a constructive and appropriate contract.

S. Elworthy née Wilks, Cranbrook DOI: 10.1038/sj.bdj.2014.9

\section{FLUORIDATION}

\section{Advocating public health measures}

Sir, I am writing to thank you for your thought-provoking editorial: Do we really care about caries? (BDJ 2013; 215: 313).

Since its formation in 1969, the British Fluoridation Society has been working to promote the implementation of water fluoridation schemes. Our aim is to improve oral health and address inequalities, in particular to prevent childhood caries and avoidable extractions under general anaesthetic. While there is a clear link between deprivation and caries, the figures from the National Dental Epidemiological Programme for England also show that when a deprived area has a fluoridated water supply it can achieve better caries rates than other more affluent areas. Fluoridated Birmingham, for example, ranks higher in the index of multiple deprivation than non-fluoridated Leicester but has a lower $\mathrm{dmft}>0$ score (32.7\% and 53.2\% respectively).

We fully endorse your view that dental professionals have a crucial role to play in advocating for public health measures such as water fluoridation. Since April 2013, local authorities are responsible for consulting with the public and deciding if new schemes should go ahead. They can also consult on the termination of existing schemes. The anti-fluoridation lobby is small but extremely vocal and not afraid to put pressure on local authorities. In areas where this is an issue, to write to your local councillor and encourage your patients to do the same would be invaluable. For more information go to www.bfsweb.org. DOI: 10.1038/sj.bdj.2014.11 